\title{
УДК:633.15:631.527.5:581.1 https://doi.org/10.53040/gppb7.2021.34 \\ ВЛИЯНИЕ ХОЛОДОВОГО СТРЕССА НА НЕКОТОРЫЕ ПРИЗНАКИ ПРОСТЫХ ГИБРИДОВ КУКУРУЗЫ
}

\author{
Клименко O.A. \\ Институт генетики, физиологии и защиты растений, Кишинэу, Республика Молдова \\ e-mail: oxana.climenco@igfpp.md
}

\begin{abstract}
The purpose of this study was to determine the heritability of certain traits under low temperatures both at the stage of early plant development and at the haploid level, while identifying potentially stress resistant and productive hybrids. 14 simple hybrids of the first generation were used as the initial material. The variability of signs of early development of plants and male gametophyte under low temperatures was evaluated. The coefficients of heritability of maternal and paternal genotypes under stressful conditions are calculated. A reliable dependence of the variability of the "pollen grain diameter" trait on the interaction of parental genotypes with a stress factor is shown. Hybrids Mo17xN6, Mo17xW23, A285xRf7, XL12xN6, XL12xP101 were the best in terms of the characteristics studied in the experiment.

Key words: maize hybrids, cold stress, pollen.

\section{Введение}

В процессе создания гибридов кукурузы, сочетающих устойчивость к холоду и продуктивность, весьма существенным является выявление родительских генотипов с высокими коэффициентами наследуемости количественных признаков в условиях данного стресса на диплоидном и гаплоидном уровнях. Следует отметить, что в настоящее время идентифицированы гены, позволяющие определять устойчивые к пониженным температурам генотипы кукурузы на этапе прорастания семян [1], выяснены некоторые особенности механизмов устойчивости к холоду у линий кукурузы [2]. Также устойчивые к холоду популяции выделялись по всхожести и показателям роста при посеве в ранние сроки [3]. Скрининг инбредных линий кукурузы при холодовом стрессе в полевых условиях позволяет селектировать устойчивые генотипы [4]. Цель данного исследования состояла в том чтобы определить наследуемость некоторых признаков в условиях пониженных температур как на этапе раннего развития растений, так и на гаплоидном уровне, выявив при этом потенциально устойчивые и продуктивные гибриды.
\end{abstract}

\section{Материалы и методы}

В качестве исходного материала использовали простые гибриды первого поколения созданные по схемам 2х5 (материнские линии А285 и Mo17, а отцовские P165, W23, N6, P101, Rf7) и 3x4 (материнские линии A285, Mo17, XL12, а отцовские P165, N6, P101, Rf7). Линии W23 и N6 были получены от Maize Genetics Cooperation Stock Center (USA) в 2001 году. Семена гибридов обрабатывали холодом (диапазон температур от $+1^{0} \mathrm{C}$ до $+8^{0} \mathrm{C}$ ) в течение 10 дней. Учитывали такие признаки как «всхожесть семян» (\%), «длина проростка» (см) и «длина корешка» (см). Каждый генотип оценивали в трех повторностях по 30-35 семян. В полевых условиях проводились измерения и учеты следующих признаков: «высота растения» (см), «высота до первого початка» (см), «длина метелки» (см), «количество веточек метелки» (шт), «длина початка» (см), «количество рядков зерен» (шт), «количество зерен в рядке» (шт). У каждого гибрида было измерено от 5 до 10 растений. Пыльцевые зерна сеяли на питательную среду in vitro (нестерильная культура) и обрабатывали пониженными температурами (диапазон температур от $+4^{0} \mathrm{C}$ до $+15^{0} \mathrm{C}$ ) в течение 6 дней. Состав питательной среды (на 100мл): сахароза15 г, хлористый кальций -30 мг, борная кислота-10 мг, агар -600 мг. Показатели признака «диаметр пыльцевого зерна» определяли и у свежесобранных пыльцевых зерен (контроль) и у зерен, посеянных на питательную среду in vitro. Измерения выполняли с помощью микроскопа и окуляр микрометра. Для статистической обработки использовали значения выраженные в единицах окуляр микрометра. Все эксперименты были сделаны согласно требованиям двух- и трехфакторного дисперсионного анализа (схема скрещиваний, наличие минимум трех повторностей) и обработаны программой Statgraphics 5.1. На основе полученных результатов расчитывали коэффициенты наследуемости родительских генотипов [5, с.308-313], а также показатели силы влияния факторов [5, с.211-212]. 


\section{Результаты и обсуждение}

Величины коэффициентов наследуемости родительских генотипов и их взаимодействия варьировали в зависимости от схем дисперсионного анализа и признаков (таблица 1). Наибольшие значения коэффициентов наследуемости $\left(\mathrm{h}^{2}\right)$ отцовских генотипов были выявлены для признаков, характеризующих раннее развитие растения в стрессовых условиях пониженных температур («длина проростка», «длина корешка»). Материнская линия Мo17 и отцовский генотип Р101 показали лучшие значения данных признаков в гибридных комбинациях с другими генотипами данных схем скрещивания.

Кроме этого, наибольшим значением $\mathrm{h}^{2}$ для взаимодействия материнских и отцовских генотипов характеризовался признак «длина початка», причем это единственный достоверный коэффициент наследуемости по данному признаку. Интересно отметить, что наибольшие значения $\mathrm{h}^{2}$ материнских генотипов (в обеих схемах) оказались у признака «высота прикрепления первого початка» и они превосходили аналогичные значения как взаимодействия родительских генотипов, так и отцовских генотипов в отдельности. По лучшим показателям изученных количественных признаков в обычных условиях выделились гибриды Mo17xN6, Mo17xW23, A285xRf7. В целом по признакам метелки и початка в схеме $2 \times 5$ значения коэффициента наследуемости материнских генотипов имели весьма существенное значение. Однако в стрессовых условиях пониженных температур у материнских генотипов показатели $\mathrm{h}^{2}$ были невысокие (признаки «всхожесть семян», «длина проростка» в схеме $3 \mathrm{x} 4$ ), а по признакам «длина корешка» и «диаметр пыльцевого зерна» оказались недостоверны.

Что касается отцовских генотипов, то на диплоидном уровне наибольшие значения коэффициентов наследуемости выявлены в схеме $2 \times 5$, а на гаплоидном уровне - в схеме $3 \times 4$. Необходимо учитывать, что при действии стресса показатели $\mathrm{h}^{2}$ отцовских генотипов и взаимодействия родительских генотипов по признаку «диаметр пыльцевого зерна» были в среднем в 4,4 раза ниже, чем аналогичные значения $\mathrm{h}^{2}$ признаков «всхожесть семян», «длина проростка», «длина корешка».

Таблица 1. Значения коэффициентов наследуемости родительских генотипов у простых гибридов $\mathrm{F}_{1}$

\begin{tabular}{|c|c|c|c|c|c|c|}
\hline \multirow[t]{2}{*}{ Признаки } & \multicolumn{2}{|c|}{$\begin{array}{l}\mathrm{h}^{2} \text { материнских } \\
\text { генотипов }\end{array}$} & \multicolumn{2}{|c|}{$\begin{array}{c}\mathrm{h}^{2} \text { отцовских } \\
\text { генотипов }\end{array}$} & \multicolumn{2}{|c|}{\begin{tabular}{|c|}
$\mathrm{h}^{2}$ взаимодействия \\
материнских и \\
отцовских генотипов
\end{tabular}} \\
\hline & $2 \times 5$ & $3 \times 4$ & $2 \times 5$ & $3 \times 4$ & $2 \times 5$ & $3 \times 4$ \\
\hline Всхожесть семян (стресс) & - & $0,1102 * * *$ & $0,6297 * * *$ & $0,1025 * * *$ & $0,137 *$ & $0,5121 * * *$ \\
\hline Длина проростка (стресс) & - & $0,0271 * * *$ & $0,7648 * * *$ & $0,5143 * * *$ & - & $0,2526 * * *$ \\
\hline Длина корешка (стресс) & - & - & $0,7922 * * *$ & $0,2445 * * *$ & - & $0,637 * * *$ \\
\hline Высота растения & $0,1596 * *$ & $0,0752 * * *$ & $0,1831 * *$ & - & - & $0,4984 * * *$ \\
\hline Высота до первого початка & $0,3286 * * *$ & $0,4868 * * *$ & $0,1316 * *$ & - & - & $0,1659 * *$ \\
\hline Длина метелки & $0,2008 * * *$ & $0,0006^{*}$ & $0,102 * * *$ & - & $0,2602 * *$ & $0,4384 * * *$ \\
\hline Количество веточек метелки & $0,3014 * * *$ & $0,2175^{* * *}$ & $0,216 * * *$ & $0,184 * * *$ & $0,174 * *$ & $0,2417 * *$ \\
\hline Длина початка & - & - & - & - & - & $0,7066^{* * *}$ \\
\hline Количество рядков зерен на початке & $0,3631 * * *$ & $0,1368^{*}$ & $0,3527 * * *$ & $0,4663 * * *$ & - & - \\
\hline Количество зерен в рядке & - & - & $0,242 * * *$ & - & $0,1878 * *$ & $0,6587 * * *$ \\
\hline Диаметр пыльцевого зерна (стресс) & - & - & $0,1365 * *$ & $0,1626 * * *$ & - & $0,1332 *$ \\
\hline
\end{tabular}

$*_{-}$p $<0,05 ; * *-p<0,01 ; * * *-p<0,001$

Результаты трехфакторного дисперсионного анализа (таблица 2) изменчивости признака «диаметр пыльцевого зерна» показали достоверную зависимость варьирования данного признака от таких факторов как «материнские генотипы» (А), «отцовские генотипы» (В), «холодовой стресс» (С), от двухфакторного взаимодействия «материнские генотипы» $\mathrm{X}$ «холодовой стресс» (АС) и от трехфакторного взаимодействия «материнские генотипы» $\mathrm{x}$ «отцовские генотипы» $\mathrm{x}$ «холодовой стресс» (ABC).

Величина зависимости изменчивости признака мужского гаметофита от стрессового фактора была в среднем примерно в 7 раз больше чем аналогичные показатели как родительских генотипов по отдельности, так и их взаимодействий с фактором «холодовой стресс». Показатель силы влияния материнских генотипов был выше аналогичного значения отцовских генотипов. Парные взаимодействия фактора «отцовские генотипы» с двумя другими факторами оказались недостоверными. Величина силы влияния трех факторов вместе довольно низкая, но уступает такому же 
Таблица 2.Результаты трехфакторного дисперсионного анализа признака «диаметр пыльцевого зерна» у простых гибридов $\mathrm{F}_{1}$ (схема $\left.3 \mathrm{x} 4\right)$

\begin{tabular}{|l|c|c|c|c|c|}
\hline \multicolumn{1}{|c|}{ Дисперсия } & $\begin{array}{c}\text { Сумма } \\
\text { квадратов }\end{array}$ & $\begin{array}{c}\text { Степени } \\
\text { свободы }\end{array}$ & $\begin{array}{c}\text { Средний } \\
\text { квадрат }\end{array}$ & $\begin{array}{c}\mathrm{F} \\
\text { фактическое }\end{array}$ & $\begin{array}{c}\text { Сила } \\
\text { влияния, \% }\end{array}$ \\
\hline материнские генотипы (А) & 3589,33 & 2 & 1794,7 & 7,08 & $5,0^{* *}$ \\
\hline отцовские генотипы (В) & 2324,7 & 3 & 774,9 & 3,06 & $3,26^{*}$ \\
\hline холодовой стресс (С) & 20449,2 & 1 & 20449,2 & 80,65 & $28,7^{*}$ \\
\hline $\mathrm{AB}$ & 1767,6 & 6 & 234,6 & 1,16 & - \\
\hline $\mathrm{BC}$ & 529,01 & 2 & 264,5 & 1,04 & - \\
\hline $\mathrm{AC}$ & 2755,5 & 3 & 918,5 & 3,62 & $3,87^{*}$ \\
\hline $\mathrm{ABC}$ & 3226,43 & 6 & 537,7 & 2,12 & $4,53^{*}$ \\
\hline остаточная & 36513,1 & 144 & 253,6 & & \\
\hline общая & 71155,0 & 167 & & & \\
\hline $\mathrm{R}^{2}$ всей модели, \% & 48,7 & & & & \\
\hline
\end{tabular}

$*$ - $<<0,05$ и **-p $<0,01$

значению материнских генотипов. Материнские линии достоверно отличались друг от друга по среднему значению признака «диаметр пыльцевого зерна» (лучшей оказалась А285), но у отцовских генотипов между тремя лучшими по данному показателю генотипами достоверной разницы не было. При этом величина самого признака у материнских линий в среднем была выше чем у отцовских. По результатам множественного сравнительного анализа (с использованием $\mathrm{HCP}_{0,05}$ ) найдены лучшие по данному признаку гибриды: XL12xP101, Mo17xN6 и XL12xN6.

\section{Выводы}

В условиях стрессовых пониженных температур на ранних этапах развития растений и на гаплоидном уровне наибольшие величины коэффициентов наследуемости были отмечены у отцовских генотипов и взаимодействия родителей.

Наиболее высокие значения коэффициентов наследуемости материнских генотипов были выявлены у признаков, характеризующих само растение и метелку. При этом такие признаки как «длина початка» и «количество зерен в рядке» характеризовались самыми высокими показателями наследуемости взаимодействия родительских генотипов.

Генотипы Mo17, N6, W23, A285, Rf7, XL12 можно использовать в создании исходного материала для селекции холодостойких и продуктивных гибридов.

Данные исследования были представлены в рамках проекта Государственной Программы 20.80009.5107.03 «Эффективное использование генетических ресурсов растений и современных биотехнологических методов для повышения адаптивности сельскохозяйственных культур к климатическим изменениям» финансируемой Национальным Агенством по Исследованиям и Развитию.

\section{Литература}

1. SILVA-NETA, I.C., PINHO, E.V., VEIGA, A.D., PÌNHO, R.G., GUIMARÃES, R.M., CAIXETA, F., SANTOS, H.O., MARQUES, T.L. Expression of genes related to tolerance to low temperature for maize seed germination. (2015) Genet. Mol. Res 30; 14(1):2674-90. doi: 10.4238/2015.March.30.28.

2. SOBKOWIAK, A., JOŃCZYK, M., ADAMCZYK, J., SZCZEPANIK, J., SOLECKA, D., KUCIARA, I., HETMAŃCZYK, K., TRZCINSKA, DANIELEWICZ I., GRZYBOWSKI, M., SKONECZNY, M., FRONK, J. SOWIŃSKI, P. Molecular foundations of chilling-tolerance of modern maize. (2016) BMC Genomics 17:125 https://doi.org/10.1186/s12864-016-2453-4

3. RODRI'GUEZ, V.M., ROMAY, M.C., ORDA'S, A., REVILLA, P. Evaluation of European maize (Zea mays L.) germplasm under cold conditions. Genet Resour Crop Evol (2010) 57:329-335 DOI 10.1007/s10722-0099529-9 https://link.springer.com/content/pdf/10.1007/s10722-009-9529-9.pdf

4. MEENA, H.S., MISHRA, U., GADAG, R.N., PATHAK, H. Cold Tolerance in Maize (Zea mays): Physiological and Morphological Traits. (2015) International Journal of Tropical Agriculture Vol. 33, No. 4, p.2603-2607. https://www. researchgate.net/publication/326736049_Cold_tolerance_in_maize_zea_Mays_Physiological_and_morphological_traits

5. ДОСПЕХОВ, Б.А. Методика полевого опыта (с основами статистической обработки результатов исследований). - М.: Агропромиздат, -1985.- 352 с. 